\section{Australian scientific know-how commercially exploited}

\section{Sydney}

LIKE the inhabitants of other Englishspeaking nations, Australians believe their past record shows them to be strong on originality but weak on turning ideas into commercial products.

Now, two inventions - a fast Fourier transform (FFT) VLSI chip and the Sarich bad old habits can be broken.

The list of inventions on which Australia has failed to capitalize is truly impressive. In the last century, Australia was first with the ice-making plant - but its ice, full of air bubbles, was rejected by consumers in favour of more expensive natural lake ice imported from North America. Next came the light bulb, independently developed a month after Edison's success. More recent failures are the 'black-box" aircraft flight recorder, produced overseas because Australian civil aviation authorities refused to back it, and the Interscan aircraft instrument approach and landing system. Interscan was developed by the Commonwealth Scientific and Industrial Research Organization (CSIRO) Radiophysics Division and chosen as a world standard but no Australian manufacturer could be found. CSIRO collects only a small royalty while the profits from millions of dollars worth of sales go to other countries.

CSIRO Radiophysics Division also developed a programmable computer at the same time as the United States and the United Kingdom. Their 2,000 vacuum tube machine, CSIRAC, was fully operational in 1951, the year the first commercial computer was produced by Ferranti. But according to Dr E.G. Bowen, then head of the division, further development was killed by three reports, two from British scholars recommmending that Australia concentrate on agriculture, and a third from Australia concluding that the future belonged to analogue, not digital, computers.

The Radiophysics Division has now come up with the FFT VLSI chip. Its designers claim that it can perform a fast Fourier transform a hundred times faster than the $\$ 150,000 \mathrm{VAX}$ computer and will make tasks like the construction of images by medical scanners possible in real time, rather than after a 15 minute processing delay. According to Dr Bob Frater, the present division chief, the FFT chip has the potential to be to digital signal-processing what the microprocessor is to computing. Determined not to let a third invention slip away, the division is vigorously persuading Australian companies of its commercial potential. engine - have come along to test whether
CSIRO's new masters at the Department of Industry, Trade and Commerce are also anxious not to let opportunities disappear abroad. Along with the Western Australian government, they have invested $\mathrm{A} \$ 500,000$ in a manufacturing feasibility study of an engine developed from the revolutionary design of a West
Australian, Ralph Sarich. It is a lightweight three-cylinder, two-stroke engine using the orbital fuel injection system developed by Sarich for an engine that relied on combustion around the inside of a drum to rotate an internal core. The Sarich two-stroke is claimed to be cheaper to produce, have fewer parts and use less fuel than normal engines. If Australian industry wakes up there is, says a government spokesman, a market for 250,000 engines a year, with potential exports worth $\mathrm{A} \$ 1,100$ million. Charles Morgan

\section{New science prizes awarded to two Italians, one West German}

\section{Munich}

THE first Italgas prizes have just been awarded in Italy. The recipients - a West German physicist, an Italian energy researcher, and an Italian computer scientist - each received 100 million Italian lire (about $\$ 76,000$ ) from the Italian natural gas company Societa Italiana per il Gas (Italgas) at a ceremony in Turin on 9 October. The money can be used in any way the winner chooses.

The Italgas Prizes, awarded only to scientists in EEC (European Economic Community) countries, are quite lucrative. By comparison, Nobel prizes bring about $\$ 340,000$ for each category; the renowned Albert Lasker awards, given in the United States, are worth only $\$ 15,000$ divided among the winners.

The prizes will be awarded for at least the next ten years to researchers in three broad areas -- physics and chemistry, environmental and energy science, and materials science, communications and information science. Researchers are chosen for outstanding achievement and deep involvement in their fields; significant progress at a young age is given priority, as is research that has to do with natural gas.

This year's winners were Theodor Hänsch, 47, a physicist at the LudwigMaximilian University in Munich; Mario Silvestri, 68, a professor of energetics at the Polytechnic of Milan; and Raffaele Meo, 52, a professor of information systems at the Polytechnic of Turin.

Hänsch has distinguished himself with his work in laser spectroscopy. He has developed techniques for very-high- resolution laser spectroscopy and applied them to atomic hydrogen and other simple atomic systems. By comparing the results of these very precise experiments with theory, Hänsch can test basic laws of physics in ways not possible using other methods. He hopes eventually to measure better values for fundamental constants such as the Rydberg constant or the mass of the electron. Hänsch returned to West Germany in 1986 after spending 15 years at Stanford University.

Silvestri was an Italian pioneer in exploring the peaceful uses of nuclear energy before shifting to research on nonlinear thermodynamics. He collaborated from 1965 to 1976 with US, British and Canadian researchers developing heavywater and boiling-water reactors.

Meo used his expertise in digital signal processing to produce one of the earliest automatic voice recognition systems. He is currently interested in computer architectures and networks, and is also active in research projects sponsored by Consiglio Nazionale delle Richerche (CNR), Italy's national research council.

Nominations for the prizes are sought from universities, academies of science and private and governmental research institutions in EEC countries. This year's winners were selected from eighty good candidates, according to Italgas.

Italgas initiated the prizes to celebrate its 150 th anniversary and is currently at work at a number of other endeavours on behalf of science. Next on the list is the reopening after many years of the historic Academy of Sciences building in Turin on 31 October. Steven Dickman

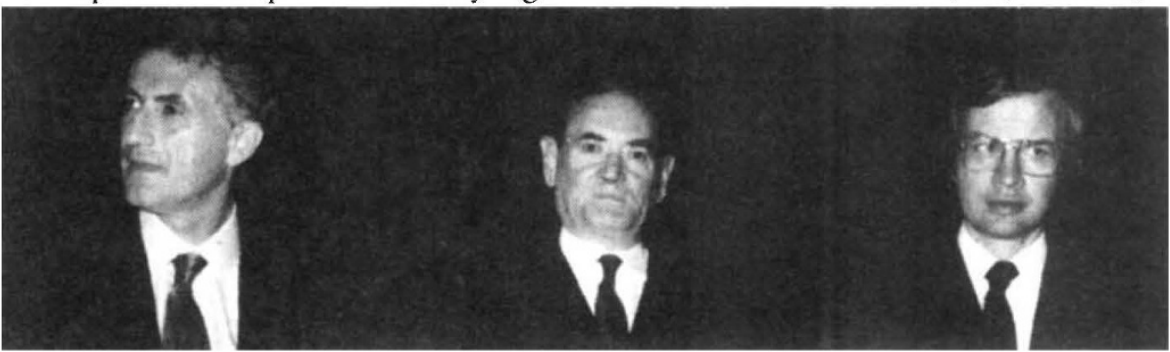

Left to right: Professors Raffaele Meo, Mario Silvestri and Theodor Hänsch. 